\title{
Article \\ Characterisation of Neurospheres-Derived Cells from Human Olfactory Epithelium
}

\author{
Elena A. Zelenova ${ }^{1}$, Nikolay V. Kondratyev ${ }^{1, *}$ (D) Tatyana V. Lezheiko ${ }^{1}$, Grigoriy Y. Tsarapkin ${ }^{2}$, \\ Andrey I. Kryukov ${ }^{2}$, Alexander E. Kishinevsky ${ }^{2}$ (D), Anna S. Tovmasyan ${ }^{2}$, Ekaterina D. Momotyuk ${ }^{3,4}$, \\ Erdem B. Dashinimaev ${ }^{3,4}$ (D) and Vera E. Golimbet ${ }^{1}$ \\ 1 Mental Health Research Center, 115522 Moscow, Russia; zelenova@gmail.com (E.A.Z.); \\ lezheiko@list.ru (T.V.L.); golimbet@mail.ru (V.E.G.) \\ 2 Sverzhevskiy Otorhinolaryngology Healthcare Research Institute, Moscow Department of Healthcare, \\ 117152 Moscow, Russia; tsgrigory@mail.ru (G.Y.T.); nikio@zdrav.mos.ru (A.I.K.); voroej@gmail.com (A.E.K.); \\ 7svetlana@mail.ru (A.S.T.) \\ 3 Koltzov Institute of Developmental Biology of Russian Academy of Sciences, 119991 Moscow, Russia; \\ edm95r@rambler.ru (E.D.M.); dashinimaev@gmail.com (E.B.D.) \\ 4 Center for Precision Genome Editing and Genetic Technologies for Biomedicine, Pirogov Russian National \\ Research Medical University, 117997 Moscow, Russia \\ * Correspondence: nikolay.quadrat@gmail.com
}

\section{check for} updates

Citation: Zelenova, E.A.; Kondratyev, N.V.; Lezheiko, T.V.; Tsarapkin, G.Y.; Kryukov, A.I.; Kishinevsky, A.E.; Tovmasyan, A.S.; Momotyuk, E.D.; Dashinimaev, E.B.; Golimbet, V.E. Characterisation of Neurospheres-Derived Cells from Human Olfactory Epithelium. Cells 2021, 10, 1690. https://doi.org/ $10.3390 /$ cells 10071690

Academic Editor: Stefan Liebau

Received: 31 May 2021

Accepted: 30 June 2021

Published: 4 July 2021

Publisher's Note: MDPI stays neutral with regard to jurisdictional claims in published maps and institutional affiliations.

Copyright: (c) 2021 by the authors. Licensee MDPI, Basel, Switzerland. This article is an open access article distributed under the terms and conditions of the Creative Commons Attribution (CC BY) license (https:// creativecommons.org/licenses/by/ $4.0 /)$.

\begin{abstract}
A major problem in psychiatric research is a deficit of relevant cell material of neuronal origin, especially in large quantities from living individuals. One of the promising options is cells from the olfactory neuroepithelium, which contains neuronal progenitors that ensure the regeneration of olfactory receptors. These cells are easy to obtain with nasal biopsies and it is possible to grow and cultivate them in vitro. In this work, we used RNAseq expression profiling and immunofluorescence microscopy to characterise neurospheres-derived cells (NDC), that simply and reliably grow from neurospheres (NS) obtained from nasal biopsies. We utilized differential expression analysis to explore the molecular changes that occur during transition from NS to NDC. We found that processes associated with neuronal and vascular cells are downregulated in NDC. A comparison with public transcriptomes revealed a depletion of neuronal and glial components in NDC. We also discovered that NDC have several metabolic features specific to neuronal progenitors treated with the fungicide maneb. Thus, while NDC retain some neuronal/glial identity, additional protocol alterations are needed to use NDC for mass sample collection in psychiatric research.
\end{abstract}

Keywords: olfactory epithelium; neuronal progenitors; olfactory ensheathing cells; RNA expres-sion; maneb

\section{Introduction}

Compared to most other disease research, the arsenal of tools for psychiatric research is limited by the lack of reliable biomarkers, the small selection of animal models, and the poor availability of brain tissue. In recent years, studies of genetic and epigenetic factors of mental illness have revealed that most of them are associated with impaired embryonic development of the brain [1-4]. Since it is impossible to obtain foetal brain samples from future mentally ill people, the study of neuronal stem cells in vitro is the next best thing. This makes the use of neuronal cells in vitro a priority object for model research in psychiatry [5,6]. A common procedure for obtaining such cells is to grow neuronal progenitors and neurons from induced pluripotent cells. This model was used to show a decrease in the expression of protocadherins in schizophrenia [7], impaired $\beta$-catenin/BRN2 cascade for idiopathic autism [8], lithium-dependent hyperexcitability [9] and altered calcium signalling pathway [10] in bipolar disorder. Such studies are usually limited to small numbers, often less than 10 samples. The problem with this small sample 
size is that common mental illnesses are mostly hereditary and highly polygenic [11]. In the past, it was hoped that numerous genetic risk factors would converge into a small number of easily identifiable biological predictors of the disease, which in psychiatric genetics are usually called "endophenotypes" as opposed to the largely subjective behavioural symptoms used in the diagnosis of the diseases [12]. However, it seems that small samples are not enough to reveal endophenotypes, especially for diagnostic purposes. For example, some research groups reported the existence of a presynaptic deficit in the study of induced neurons from cells of patients with schizophrenia [13-15], while others have not found such an effect $[7,16]$. Lack of control for genetic factors may be a source of bias in experimental designs based on diagnostic criteria [17]. In addition, cellular protocols for obtaining neuronal cells from induced pluripotent cells are time-consuming, expensive, and notoriously hard to reproduce [18].

Neural stem cells from adult humans are an alternative source of neuronal stem cells. Neuronal stem cells of the adult brain are few in number and are available for research only post mortem. Another source is the stem cells from the peripheral nervous system. Of these, probably the most studied are the stem cells of the olfactory neuroepithelium, which during a person's life restore the olfactory receptors in a manner similar to the embryonic central nervous system development [19-22]. Cells of the olfactory neuroepithelium are of practical importance for studying the loss of smell, especially recently, in the context of COVID-19 infection [23,24], regenerative medicine [25,26], and Parkinson's disease treatment [27]. In psychiatry, studies based on cultured neural progenitor cells derived from olfactory neuroepithelium (also known as "CNONs") were used to explore the features of gene expression, epigenetic markers, and the 3D-genome associated with schizophrenia [28,29]. The use of such cells makes it possible to collect more than a hundred individual samples. Alternatively, the neuronal cells from olfactory epithelium could be obtained directly from neurospheres, which in turn could be reliably grown from primarily cultures from biopsies. Such cells ("olfactory neurosphere-derived cells", ONS) were utilised in a largescale study of gene expression of schizophrenia and Parkinson's disease [30]. The authors reported that gene expression in ONS were different and enriched by gene ontologies, for example "ephrin receptor signaling" and "axonal guidance signaling" for schizophrenia, "aryl hydrocarbon receptor signaling" and "purine metabolism" for Parkinson's disease, and "NRF2-mediated oxidative stress response" for both. Of note, there were no such enrichments when the fibroblasts were used as starting material. These achievements make the approach a promising method to study psychiatric and neurological diseases, especially relevant in genetic context where sample size is the key or in epigenetic context where minimal cell handling is required.

Nasal biopsies usually contain cells from two types of epithelial tissues: olfactory and respiratory. According to the sequencing of transcriptomes of single cells (scRNA-seq), the cytological diversity of the epithelium of the nasal sinuses includes at least 25 cell types [31]. Most of the cells in biopsies are not neuronal, so the researcher's task is to separate these neuronal cells from the resulting biopsies. Among neuronal cells, nasal biopsies include olfactory receptor cells, olfactory ensheathing cells (OEC), and neuronal stem cells (globose basal cells). Olfactory ensheathing cells are analogues of glial cells for neurons of the olfactory epithelium, which are somewhat similar to the radial glia of the embryonic brain [32]. Therefore, they, as well as neuronal stem cells of the olfactory epithelium, are of interest to the study of mental illness.

The existing protocols involve obtaining neuronal or glial stem cells from neurospheres (NS) that are to be grown from nasal biopsy material on a neuronal selective medium. In a standard medium with serum, cells arise from NS by enzymatic dissociation using trypsin to propagate into an abundant monolayer of cells within two to three weeks, which we further refer to as neurospheres-derived cells (NDC). The aim of this work is to characterize these cells and, if possible, understand how the protocol can be modified to yield more cells with neuronal or glial identity. 


\section{Materials and Methods}

2.1. Materials and Reagents

2.1.1. Cell Biology

DMEM/F12, cat. C470п(PanEco, Moscow, Russia); Fetal Bovine Serum, qualified, One Shot format, Brazil, Gibco, cat. A3160802 (Thermo Fisher Scientific, Waltham, MA, USA); GlutaMAX Supplement, Gibco, cat. 35050061 (Thermo Fisher Scientific, Waltham, MA, USA); ITS, cat. $\$ 065$ (PanEco, Moscow, Russia); EGF cat. CB-1101001 (PanEco, Moscow, Russia); FGF-2, cat. CB-1102021 (PanEco, Moscow, Russia); Dispase II, Sigma-Aldrich, cat. D4693 (Merck Life Science, Amsterdam, The Netherlands); Antibiotic-Antimycotic (100X), Gibco, cat. 15240062 (Thermo Fisher Scientific, Waltham, MA, USA).

\subsubsection{Immunostaining}

Purified anti-Nestin Antibody, cat. 656802 (Biolegend, San Diego, CA, USA); AntiGFAP Antibody, cat. 840001 (Biolegend, San Diego, CA, USA); Anti-TAGLN antibody, Sigma-Aldrich, cat. HPA019467 (Merck Life Science, Amsterdam, the Netherlands); AntiActin, $\alpha$-Smooth Muscle antibody, Mouse monoclonal, Sigma-Aldrich, cat. A5228 (Merck Life Science, Amsterdam, the Netherlands); Goat anti-Rabbit IgG $(\mathrm{H}+\mathrm{L})$ Cross-Adsorbed Secondary Antibody, Texas Red, Invitrogen, cat. T-2767 (Thermo Fisher Scientific, Waltham, MA, USA); Alexa Fluor ${ }^{\circledR} 488$ Goat anti-mouse IgG (minimal x-reactivity) Antibody, cat. 405319 (Biolegend, San Diego, CA, USA).

\subsubsection{RNA-seq}

RNeasy column kits, cat. 74104 (Qiagen, Hilden, Germany); RNAlater RNA Stabilization Reagent, cat. 76104 (Qiagen, Hilden, Germany); DNase I, cat. M0303 (NEB, Ispwich, MA, USA); CleanRNA Standard kit, cat. BC033 (Evrogen, Moscow, Russia); NEBNext Ultra II Directional RNA Library Prep, cat. E7765 (NEB, Ispwich, MA, USA); NEBNext Poly(A) mRNA Magnetic Isolation Module, cat. E7490 (NEB, Ispwich, MA, USA); NEBNext Multiplex Oligos for Illumina (Dual Index Primers Set 1), cat. E7600 (NEB, Ispwich, MA, USA).

\subsection{Sample Collection}

The study included 11 inpatients (5 women, 6 men, 25-41 y.o.) admitted to the Sverzhevsky Institute to fix the curvature of the nasal septum or hypertrophic rhinitis. Sampling of biological material from the nasal cavity was performed under general anaesthesia in the area of the upper third of the nasal septum (superior turbinate), which is a convenient site for a biopsy that contains most of the olfactory epithelium according to our and other studies [33,34]. Inclusion criteria for the study were age (20-45 y.o.) and the absence of severe somatic and mental illnesses. Exclusion criteria were the absence of chronic rhinosinusitis or acute allergic rhinitis. The collected material was placed in a tube containing $1 \mathrm{~mL}$ of DMEM/HAM F12 medium supplemented with foetal bovine serum (10\%) and Antibiotic-Antimycotic, Gibco (1\%). Samples were delivered to the laboratory within $3 \mathrm{~h}$ of biopsy collection.

\subsection{NS and NDC}

NS were obtained according to the protocol described earlier [19-22]. Biopsies were incubated with Dispase II $(2.4 \mathrm{IU} / \mathrm{mL})$ for $1 \mathrm{~h}$ at $37^{\circ} \mathrm{C}$. Further, the olfactory epithelium was separated from the lamina propria. Then the lamina propria was divided into samples with a thickness of 200 to $500 \mu \mathrm{m}$ and each sample was placed in a standard 6-well plate under a cover glass, where it was cultured for 18 days $\left(5 \% \mathrm{CO}_{2}, 37^{\circ} \mathrm{C}\right)$ in DMEM/HAM F12 supplemented with $10 \%$ foetal calf serum and antibiotics. The medium was changed every 2-3 days. After that, the cells were removed with trypsin and transplanted into flasks coated with poly-L-lysine with a density of 16,000 cells per cm2 to form NS (culture medium based on DMEM/F12 with the addition of GlutaMAX, 1\% ITS, $50 \mathrm{ng} / \mathrm{mL}$ EGF, $25 \mathrm{ng} / \mathrm{mL}$ FGF2). After 15-20 days, the formed neurospheres were collected. Some of them 
were frozen for RNA isolation using the protective reagent RNALater, the remaining ones were dissociated with trypsin and transplanted onto Petri dishes, cultured in DMEM/F12 medium supplemented with 10\% FBS, GlutaMAX, and an antibiotic. After three passages, the cells were harvested and frozen for RNA isolation.

\subsection{Fluorescent Microscopy}

NS obtained according to the protocol described above were collected and dissociated with $0.25 \%$ Trypsin-EDTA solution, after which they were planted in a 24 -well culture plate treated with poly-L-lysine, using a nutrient medium based on DMEM/F12 supplemented with glutamine, ITS 1\%, EGF (50 ng/mL), FGF2 $(25 \mathrm{ng} / \mathrm{mL})$, and incubated for a day with $5 \% \mathrm{CO} 2,37^{\circ} \mathrm{C}$. NDCs were seeded in 24-well plates using the standard design described above. NS and NDC were washed three times with PBS and fixed in $4 \%$ paraformaldehyde in PBS ( $\mathrm{pH} 7.4$ ) for $15 \mathrm{~min}$ at room temperature, after which they were washed again with PBS. Further, the cells were supplemented with primary antibodies diluted $(v / v 1: 100)$ in a "block solution" (DPBS, 10\% FBS, 0.1\% Triton X-100, 0.01\% Tween 20) and incubated for $12 \mathrm{~h}$ at $4{ }^{\circ} \mathrm{C}$. After incubation, the cells were washed three times with PBS solution, after which they were supplemented with secondary antibodies diluted $(v / v 1: 1000)$ in a block solution and incubated for $1 \mathrm{~h}$ at $37^{\circ} \mathrm{C}$. Then, the cells were washed three times with PBS solution and DAPI solution was added for nuclear staining for 15 min at room temperature. Afterwards, the cells were once again washed with PBS solution. Control wells were processed in the same way, except for the addition of primary antibodies, as well as any antibodies for "pure" control.

\subsection{RNA-seq and Expression Analysis}

RNA was isolated from the cells using RNeasy column kits (Qiagen, Hilden, Germany), then treated with DNase I and purified using the CleanRNA Standard kit (Evrogen, Moscow, Russia). The quality and quantity of the RNA were assessed with the Qubit fluorometer (Thermo Fisher Scientific, Waltham, MA, USA). cDNA libraries were constructed with $125 \mathrm{ng}$ (NS) or $500 \mathrm{ng}$ (NDC) of total RNA using NEBNext Ultra II Directional RNA Library Prep (NEB, Ispwich, MA, USA) with NEBNext Poly(A) mRNA Magnetic Isolation Module and barcoded with dual index primers for pooled sequencing. The sequencing was performed to yield 10-20 million reads ( $2 \times 150$ base pairs) per library. The gene-level estimated counts were obtained with the "salmon" tool [35]. The analysis for differentially expressed genes between 11 pairs of NS and NDC was performed with the "DESeq2" R package with sample ID used as a covariate (Love, Huber, and Anders 2014). Transcriptomic cell typing was performed using t-SNE with publicly available datasets; the SRA accession numbers are in Supplementary Table S1. Public data were reanalysed from raw FASTQ reads with salmon the same way as described above. For plots on Figures $2 \mathrm{~B}$ and 4 we used combined TPM (transcripts per million) normalised data filtered by ensembl genes which have TPM $>5$ in at least $90 \%$ of all datasets. The log-transformed TPM values were used for dimensional reduction. We utilised $\mathrm{R}$ packages "Rtsne" for t-SNE with default settings (Barnes-Hut implementation of t-SNE with initial PCA with 50 principal components and perplexity parameter specified in the text) and "umap" for UMAP with default settings ("naive" method). The same data were used for Spearman's rank correlation computations. Gene Set Enrichment Analysis was performed with "msigdbr" and "clusterProfiler" $\mathrm{R}$ packages with default parameters on a list of genes, ordered by $-\log \left(\mathrm{p}\right.$-level,adjusted) * ${ }^{*}$ sign(FC), where $p$-values and FC (fold change of expression) were taken from Deseq2 results. Net plots visualisations were generated with the "enrichplot" $R$ package [36] and the visualisation of biochemical pathways in Figure S5 was created with the help of "pathview" R package [37].

\section{Results}

We collected nasal biopsies from eleven people. We then obtained NS from the collected material and utilised a protocol described in the Methods section to grow a 
monolayer of NDC. NDC on serum-rich media produce an abundant monolayer of cells, which can be harvested and stored in nitrogen for later use.

NDC and NS were both stained with vascular markers, SMA and TAGLN (Figure 1), but NDC cultures have a portion of cells with a much more prominent SMA signal (Figures 1A and S1). The expression data support this observation: NDC have much higher ACTA2, SMA gene, $\left(\log 2 \mathrm{FC}=3.65, p=4.46 \times 10^{-22}\right)$, and TAGLN expression $\left(\log 2 \mathrm{FC}=4.87, p=9.5 \times 10^{-43}\right)$. It seems that while NDC still retain glial (GFAP) and neuronal (beta-tubulin and nestin) markers, they are shifted more towards other cell types.

From the expression analysis, it is clear that the transcriptomes of NS and NDC are different (Figure 2A). To ascertain the cellular identity of NDCs, we compared the obtained transcriptomes with previously published bulk RNAseq data of different neural progenitor cells (NPC), glial, nasal, and other (listed in Supplementary Table S1, note that there are no available RNAseq data for OEC). The clustering picture of transcriptomes on t-SNE plot suggests that while NS have transcriptomes very similar to previously published expression data from nasal biopsies, NDC are closer to the transcriptomes of cells from smooth muscle tissue and fibroblasts and not NPC (Figure 2B). Rank correlations between tested expression profiles reveal that NS to NDC transition leads to loss of similarity with glial cells ( $\rho$ falls from 0.74 to 0.58 on average) and NPC (0.51 to 0.38$)$. NDC, like NS, remain similar with smooth muscle cells ( 0.87 to 0.78 with maximum similarity with fetal aorta cells, 0.82 to 0.84 [38]) and to less extend with fibroblasts (0.82 to 0.73) (Supplementary Figure S2A). Note that the same analysis for Matigian et al. array expression data suggests that expression profiles from ONS also resemble data from fibroblasts more than NPC, glial cells, and cells in this study (Supplementary Figure S2B).

The differential expression analysis (Deseq2) of NDC vs. NS revealed that there were multiple changes in gene expression (Figure 2C, Supplementary Table S2). We had enough data for gene set enrichment analysis (GSEA) which we used to elaborate the processes involved in NS to NDC transformation. GSEA on gene ontology collection of cellular components (GO:CC) shows that energy and protein metabolism, followed by ontologies related to neuronal components, are affected the most during NS to NDC transition (Supplementary Figure S3 and Table S3). GSEA on gene ontology collection of biological processes (GO:BP) revealed a plethora of affected pathways (Supplementary Figure S4 and Table S4). There are three main themes among them: upregulated in NDC metabolic processes (mainly energetic), downregulated vascular transformation, and neuronal morphogenesis (Supplementary Figure S4). The same three themes are present in the GSEA analysis of pathway enrichment for KEGG [39] (Supplementary Table S5), WikiPathways [40] (Supplementary Table S6), and MSigDB Hallmark [41] (Supplementary Table S7) pathways collections. Some representative GSEA enrichment score curves are presented in Figure 3A. The interaction of affected genes in the "vascular" and "neuronal" categories are presented on the net plot in Figure 3B. Note that both groups of genes contain considerable intersection, involved both in neuro- and vasculogenesis, namely MAPK1, VEGFA, APOE, $N R P 1$, and others. 
A

NS

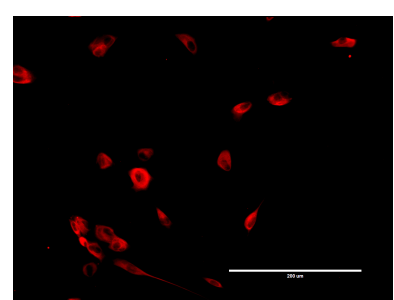

NDC

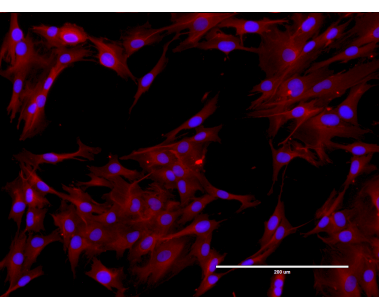

TAGLN
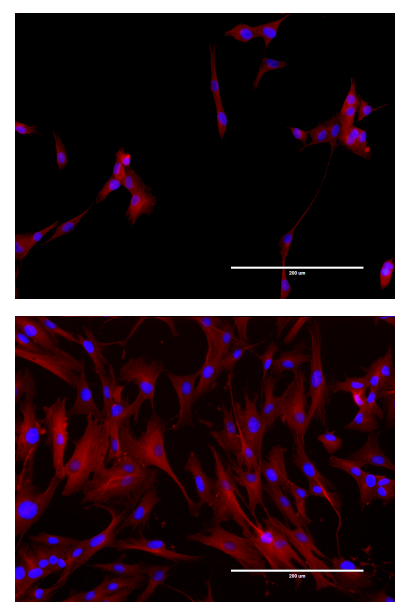

TAGLN
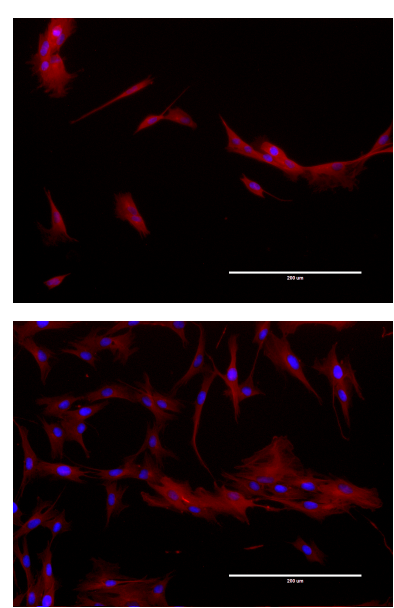

SMA
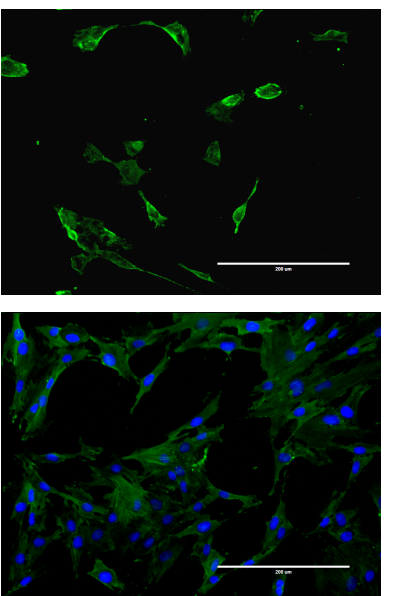

bTUB
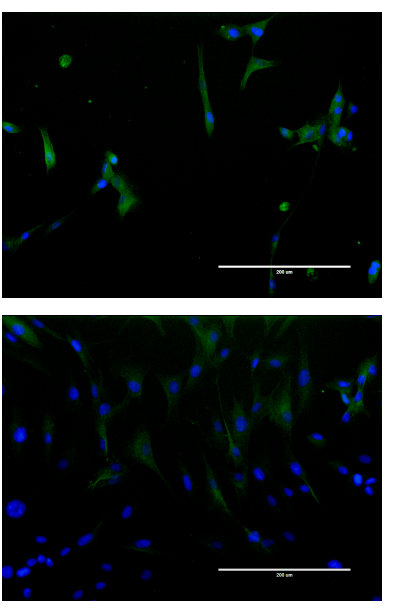

NES
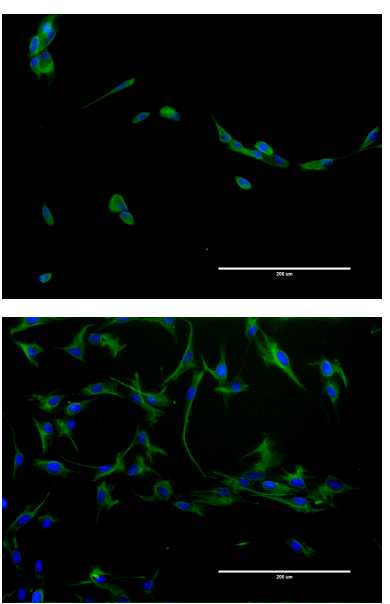

merged
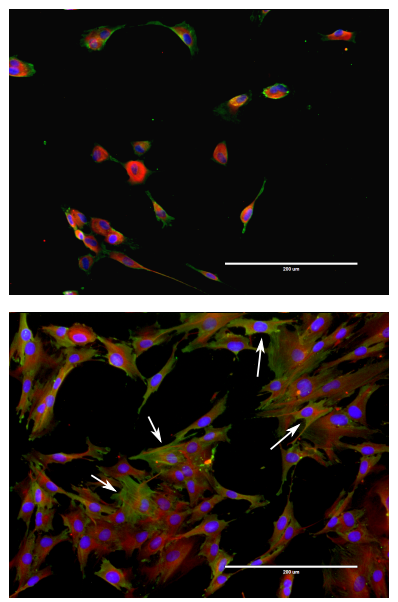

merged
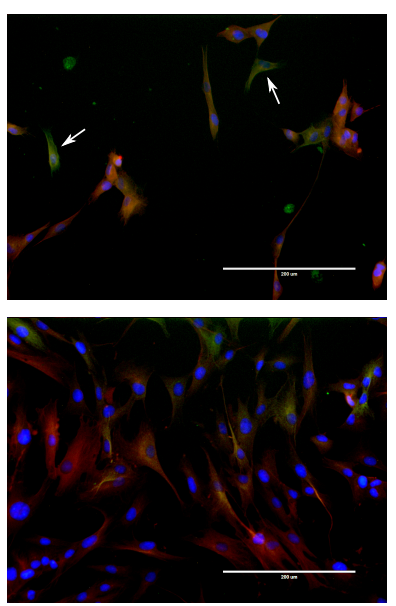

merged
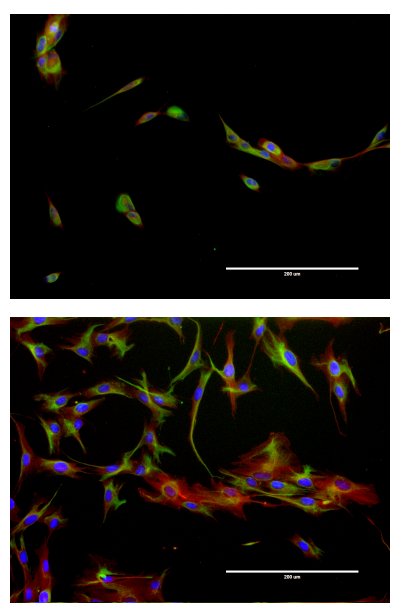

Figure 1. Vascular, glial, and neuronal markers of neurospheres (NS) and neurospheres-derived cells (NDC). (A) NS and NDC are stained with GFAP and smooth-muscle actin alpha ( $\alpha$-SMA). The arrows indicate NDC with more pronounced SMA staining. (B) NS and NDC are stained with transgelin (TAGLN) and beta-III-tubulin. The arrows indicate cells from NS with beta-III-tubulin staining. (C) NS and NDC are stained with transgelin (TAGLN) and nestin (NES). On all panels where the blue colour is present, it corresponds to DAPI dye. 


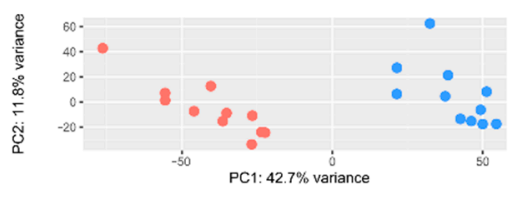

cells $\bullet$ NS $\bullet$ NOC

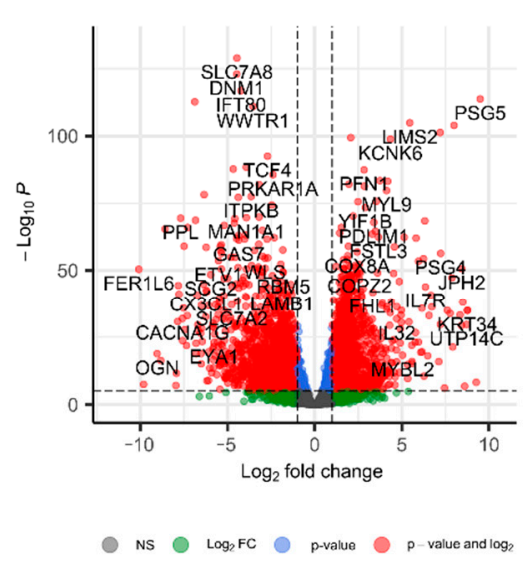

B

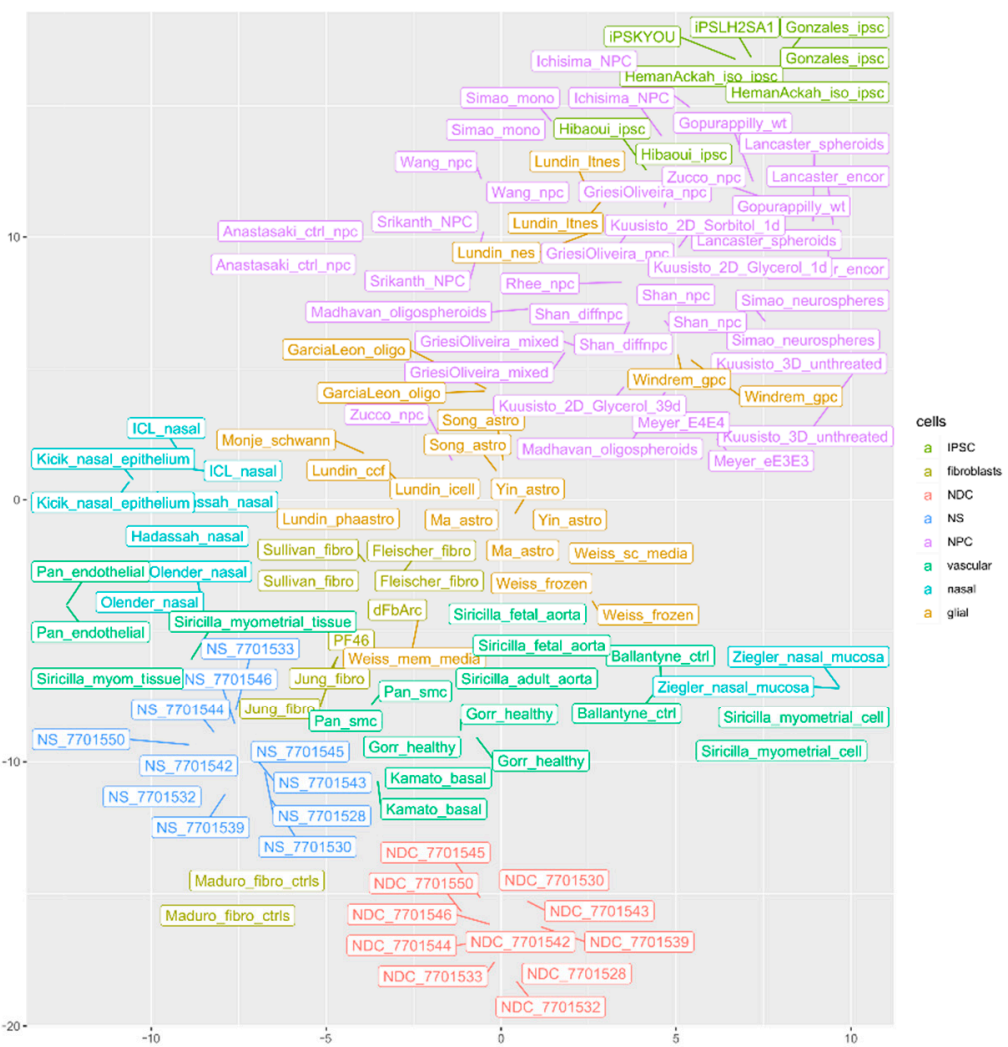

Figure 2. NDC and NS transcriptomes. (A) Principal component analysis of NDC and NS transcriptomes. (B) t-SNE plot (with perplexity parameter, $p=15$ ) of NS, NDC, and other transcriptomes from: NPC and mixed stem neuronal cells, IPSC, fibroblasts, various cells from nasal biopsies, glial cells, vascular cells, and fibroblasts; the complete list is in Table S1 in the Supplementary File. (C) Volcano plot of NDC vs. NS results of differential expression analysis with Deseq2.

To understand why NDC are further from neuronal cell identity than NS, we compared our cells with a large publicly available cytotoxicity RNAseq study of in vitro 2D-cultures of neuronal progenitors [42]. Various dimensional reduction plots demonstrate that the transcriptomic position of NPC treated with the fungicide maneb (manganese ethylenebis-dithiocarbamate) is very robustly found colocalized with positions of data from NDC (Figure 4). Another notable feature (less prominent by a wide margin though) is cadmiumtreated NPC; the effect is best seen on PCA plot (Figure 4B). Spearman's rank correlation of expression profiles of NDC and Kuusisto et al. data were not the highest for NPC treated with maneb (the highest correlation was for trans-retinoic acid, $\rho=0.73$ ), but for maneb we observed the highest and the only major increase in similarity from NS to NDC (0.59 to 0.7$)$ for all of the tested datasets. 
A
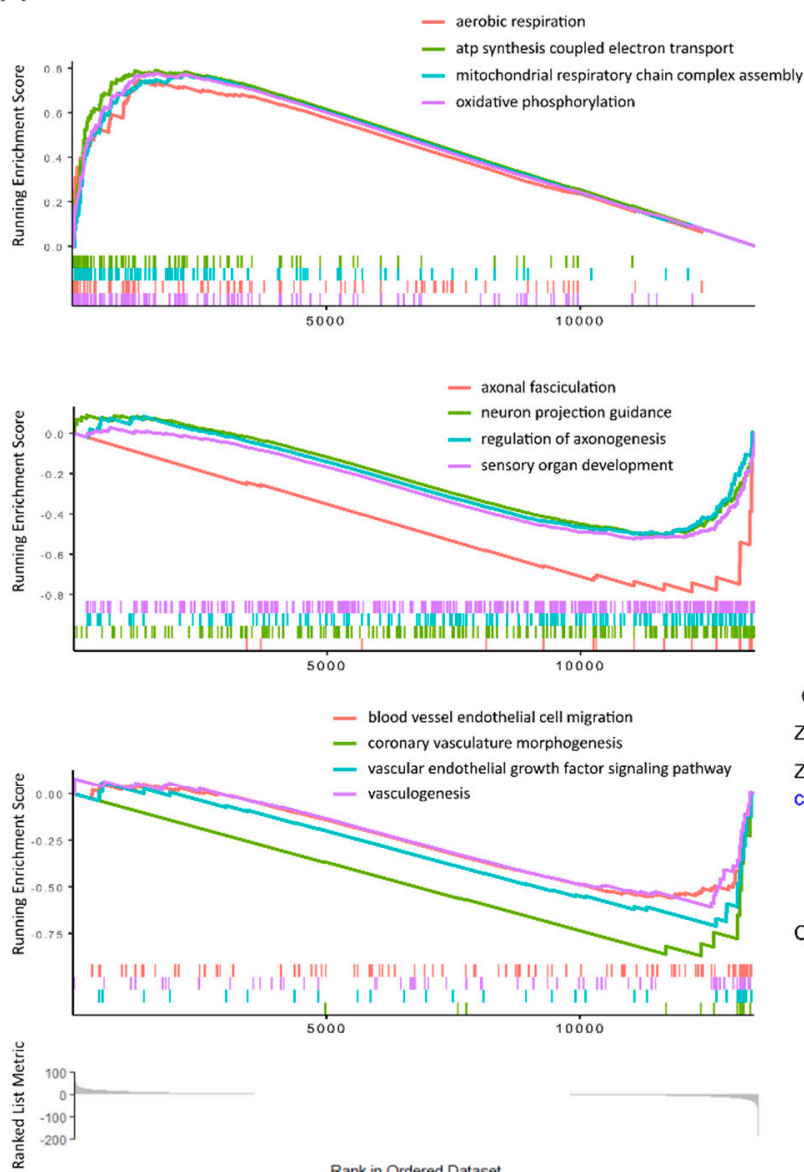

B

THRB SIX4 LRP6COL BAD NIPB BFSP1 SLC17A7 SLC25A25 TOPORS LRIG1 HIPK2 MYH15. BCL2L11

PRRX1 WHRN PTNARHGAP35

FRZB XRN2 PRRX1 MAN2A1 ALDH1A3

SPRED3 BMP4 RORB MERTK ODCHS1 VANGL2

CC2D2A sRIP11

SERPINF1" SMCHD1 MDM1/TENM3 I PTPN11 MAPK1 RHOJ TSHZ AHI KLL4 SOX8 GL12 GAP STRA6 XSH3PXD2B BMP5 SOS1 GLI3

RBPJ ATPBA2 SPED2- WNT9A MYH10

TGFBR2 ATP8A2 SPRY1 MYO7A LAMA1 BMPR1B

CTNNB1 - SEC24B "SPRY2 NTN1 PDGFRA SLTI'APP PTCH1 PDGFRB FGFR1 EPHB2 ${ }^{\text {neuron projection guidance }}$ SEMA4B $\begin{array}{lll}\text { SPRED } 1 \text { ACVRL1 } & \text { NRP1 } & \text { FLRT3 SEMA4B } \\ \text { VEGFA } & \text { PTPRA }\end{array}$ BOC. LAMA2 GAB2, ETV1 SCN1B UNC5B TMEFF1 PIK3R1 SMAD4 NEO1 GAP43 NEO1 EGR2 FRT2. RPS6KA5 MATN2-

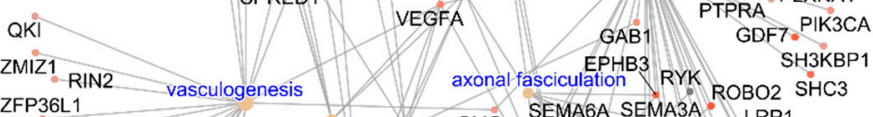
ZFP36L1 SMO SEMA6A SEMA3A ROBO2 SHC coronary-vasculature morphogenesis SMO EPHB4 MEGF8 EFNA5 CHN1 vascular endothelial growth factor signaling pathway
ROBO1- NREAMC1 AGGF1 SGCD blood vessel endothelial cell migration SLIT2 SEMA4C SEMAD"-ZSWIM6 TMEM100 TGFBR3 AMOT regulation of axonogenesis EFNB3 DRAXIN TNFRSF21 CUL APOE VASH 1 JUP JCAD SRPX2 ADAMTS3 PDPK1 SH $3 B$ P 1 ABL1 TRAK2 SPART TTL SIRT1 PIK3C2A DCN PAK1 LRP4 IST1. PIK3R3/MIA3 "SP1 RND2/ PAK3 'SYNGAP1 ANGPT1 MMRN2 AMOTL1 ADNP, MACF1 EGR3 NFE2L2

Figure 3. GSEA of GO: BP results of NDC vs. NS expression data. (A) Representative GSEA curves of significant ( $p<0.05$, Benjamini-Hochberg adjusted) biological processes: energy metabolism, neuronal, and vascular (top to bottom). Coloured stroke panels represent occurrences of individual genes, belonging to corresponding gene sets. Running enrichment scores are built on genes, ordered by ranking score [-log (Deseq2 p-level, adjusted) * sign (FC)]; the common scale is depicted at the bottom of the picture. The genes on the left are expressed more in NDC while those on the right in NS. (B) Network of downregulated in NDC individual genes, which belong to various neuronal and vascular GO:BP ontologies, enriched in GSEA (ontologies' names are in blue). The colour corresponds to $\log 2(\mathrm{FC})$; the size of the node is proportional to the size of the gene set. 
A
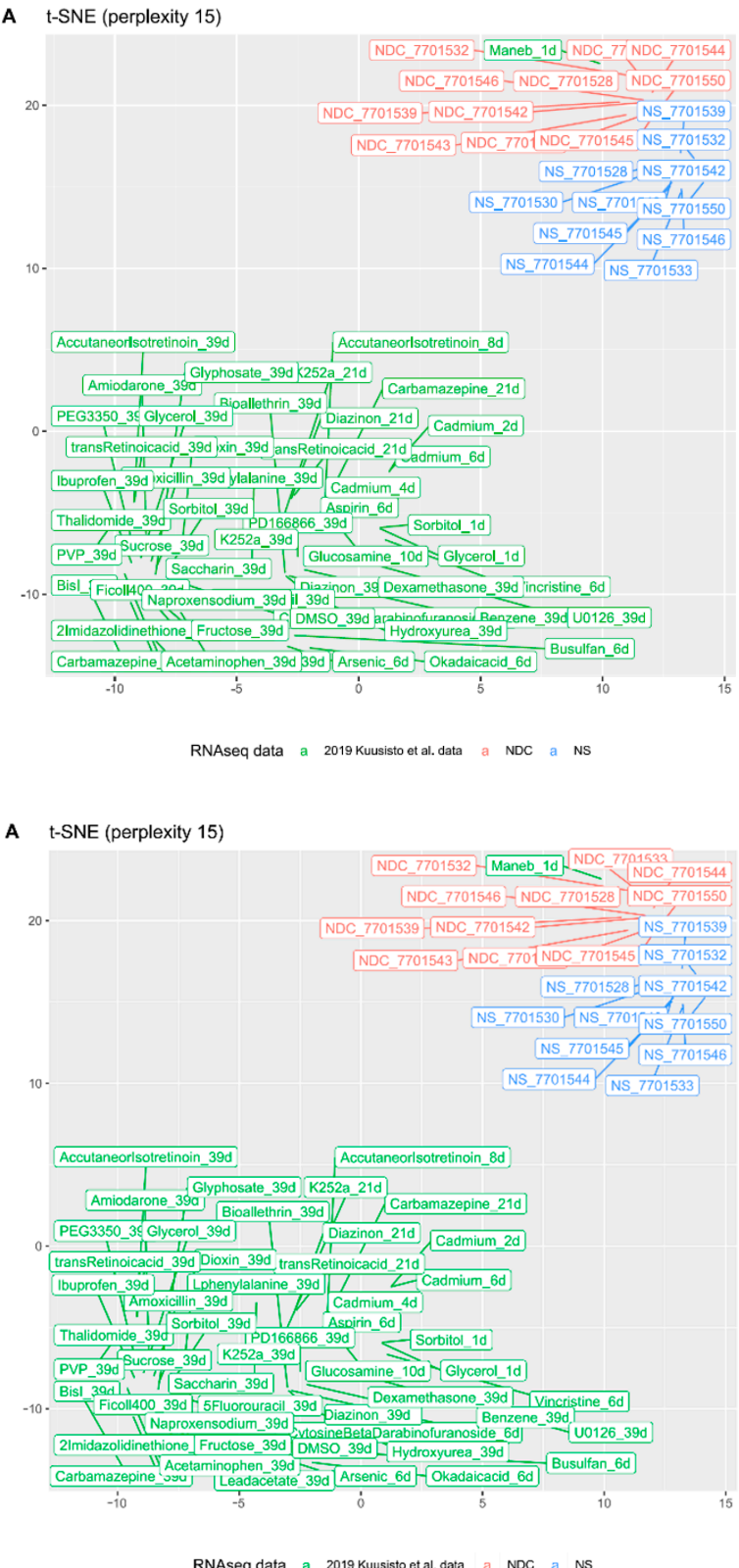

B PCA

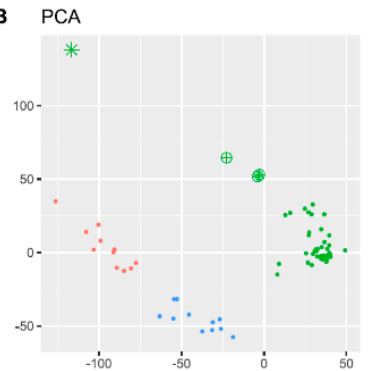

D t-SNE (perplexity 10)

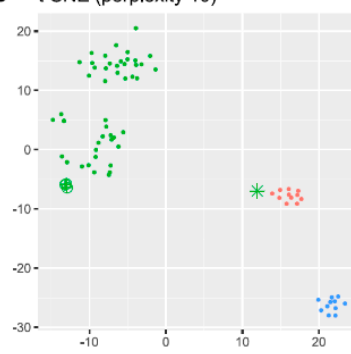

C UMAP

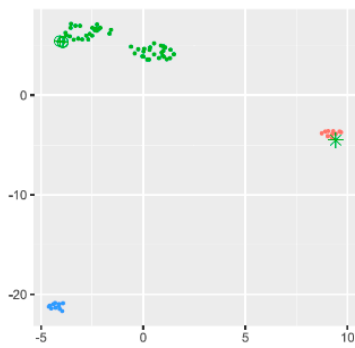

E t-SNE (perplexity 20)

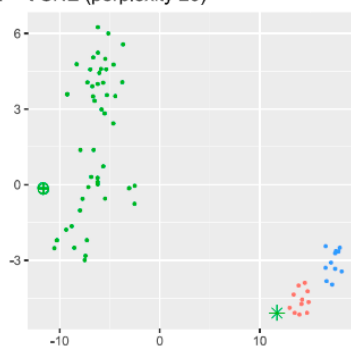

B PCA

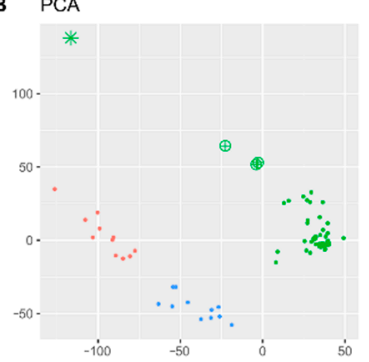

C UMAP

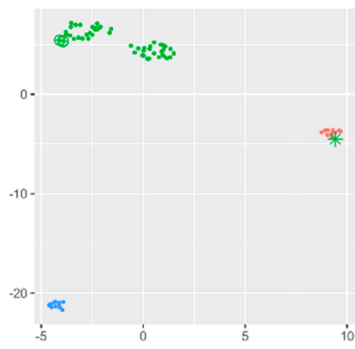

E t-SNE (perplexity 20)
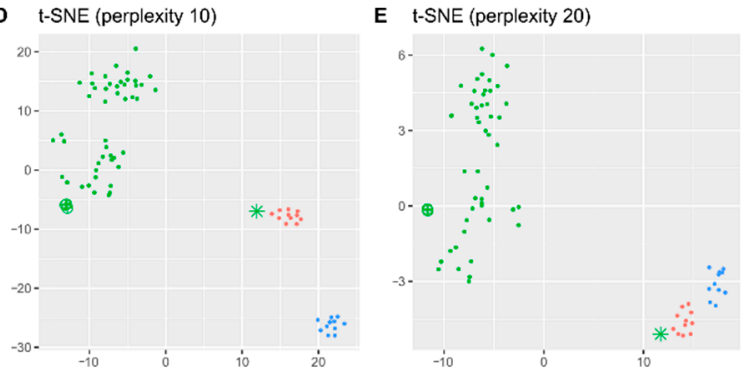

Figure 4. Transcriptomic typing with Kuusisto et al. datasets [42]. (A) The t-SNE plot (with perplexity parameter, $p=15$ ) of transcriptomic data of NS and NDC with data from the Kuusisto et al. dataset. A subset of the data was used for this picture-all substances with the longest time of exposure (up to 39 days). For cadmium, there are three points (50 $\mu \mathrm{M}$ exposure for two, four, and six days) and the only available dataset for maneb is exposure with $60 \mu \mathrm{M}$ of the substance for one day. (B-E) The same picture is visualised with PCA (B), UMAP (C), and t-SNE with $p=10$ (D) and $p=20$ (E). The point corresponding to maneb RNA-seq data is represented as an asterisk and the cadmium data as crossed circles.

\section{Discussion}

Our results show that the key problem of growing cells of neuronal origin from NS obtained from the olfactory epithelium is the balance between neural cells and non-neural cells (vascular or stromal cells, for example). The cells, originating from NS, often end up as a mixture of stem cells [43]. It is possible to further optimise cell development towards desired types. For example, in an article by Begum et al., the production of neurons from neurospheres was achieved by increasing the concentration of $\mathrm{CO}_{2}$ with a serum-free medium at the stage of neurospheres [44]. Possibly, under conditions of greater hypoxia with less reactive oxygen species (ROS) production, there are fewer stimuli for cells in the medium to develop towards vascularisation and angiogenesis [45-47]. 
Neuronal/glial and vascular markers are not mutually exclusive. For example, NPC express the smooth muscle marker SMA in mice which control their migration [48]. It was shown that OEC also express SMA and that the proportion of OEC simultaneously expressing SMA and GFAP grows with time of cultivation on the cell culture of model animals: rats, mice, hamsters, and monkeys [49,50]. Similar cells with glial, vascular, and partially neuronal markers are present with the production of spheres from other sensory organs in animals: mice hair follicle [51], porcine retina [52], and mice tongue fungiform papilla [53]. The multipotent state of those cells seems to be essential for sensory organ regeneration. The property is exploited in regenerative medicine. These kinds of cells were successfully employed for spinal injury therapy in animal models [54,55] and even in some human cases $[25,26,56]$. The particular combination of glial (GFAP) and vascular (SMA) markers was also observed for gliosarcomas, a subtype of gliomas [57-59]. It was found that the vascular component of these gliomas bears the same somatic p53 mutations as glial cells, pointing to the monoclonal origin of the glial and vascular components $[60,61]$. We observed that major cluster of ontologies of downregulated genes in NDC consists of both vascular and neuronal processes, with many shared genes (Figure 3B, Supplementary Figure S4), suggesting that in the cells of this study, the vascular markers were acquired from or even present in the original NPC and/or OEC in the olfactory biopsies.

The apparent difference between expression in NDC and Matigian et al. ONS is worth consideration. There are small but important discrepancies in protocols that could contribute to a difference in ONS and NDC. Probably the most important of these is that in the Matigian et al. protocol, primary cultures were grown in suspensions from enzymatically and mechanically dissociated biopsies. It is a suitable method for targeting the numerous neuroblasts of the olfactory epithelium of rats and mice, but it may not be very effective in humans. We used the explant method, which is supposed to be more gentle. It is also possible that both protocols work well, but stem cells from NS are unstable in their undifferentiated state, and small changes in their handling can lead to completely different outcomes.

We found that our RNA-seq NDC transcriptomes are strikingly similar with NPC transcriptomes treated with maneb. Maneb with paraquat is the basis of the environmental risk Parkinson's animal model ("MNPQ model") [62]. The Parkinson's pathway is the second of the most enriched KEGG ontologies in our GSEA analysis (Supplementary Table S5 and Figure S5), but its interpretation is not straightforward. In NDC, several principal Parkinson's markers are decreased relative to their NS expression, namely $\alpha$-synuclein gene, SNCA $(\log 2 \mathrm{FC}=-2.38, p=0.003)$, PTGDS $\left(\log 2 \mathrm{FC}=-5.48, p=1.7 \times 10^{-38}\right)$, LRRK2 $\left(\log 2 \mathrm{FC}=-3.09, p=1.47 \times 10^{-18}\right)$ [63]. Whatever stalls the neuronal progression in NDC is probably not directly related to Parkinsonian pathological process.

The reason that transcriptomes of NDC resemble NPC treated with maneb could be elevated ROS production (note, that the most enriched KEGG ontology in GSEA was "oxydative phoshorilation"). Indeed, the cytotoxicity of both maneb and cadmium is linked to elevated levels of ROS [64-66]. NDC have increased expression levels of genes of glutathione peroxidase, GPX1 $\left(\log 2 \mathrm{FC}=1.73, p=2.99 \times 10^{-14}\right)$ and superoxide dismutase 1 , SOD1 $\left(\log 2 \mathrm{FC}=0.92, p=1.02 \times 10^{-10}\right)$. As we mentioned earlier, transient ROS production is known to promote vascular growth, which is what we see in the case of NS to NDC progression. The counterpoint is that many other substances in the Kuusisto et al. screen are known to cause oxidative stress, like lead [67], permethrin [68], and isotretinoin [69]. Furthermore, Roede et al. reported that in SH-SY5Y neuroblastoma cell line, it is paraquat rather than maneb that is responsible for ROS production [70]. Anderson et al. studied the biochemistry of acute treatment of neuroblastoma cell line SK-N-AS with maneb [71,72]. They found that while energy metabolism is affected by maneb, the effect is more specific. Maneb seems to act on thiol groups of mitochondrial proteins and alter glucose metabolism by promoting gluconeogenesis at the expense of ATP production. In our NDC, we also observed multiple changes in the expression of genes involved in energetic and biochemical pathways, namely oxidative phosphorylation, nucleotide metabolism, and the citrate cycle 
(Supplementary Tables S4-S7). Still, the origin of the similarity of expression profiles in NDC and NPC treated with maneb is unclear and worthy of additional investigation.

There are some limitations to this study. First, the presented RNAseq results are acquired on bulk RNA and are not aware of the heterogeneity of NDC and NS. The immunofluorescent pictures do confirm that most of the cells bear the same markers but to a different extent, like in the case of SMA. Different methods, such as scRNA-seq, are needed to study the contribution of different types of cells in the observed effects. Second, we used dimensionality reduction of transcriptome data to contrast obtained expression profiles against publicly available data. While data from similar cell types tend to cluster together, there is no way to correct for differences in technicalities used to produce data in different laboratories and interpretation of such results should be conducted with caution. On the other hand, our second method of expression profiles comparison with rank correlations could be too conservative and misleading when correlations are too small. Most importantly, the results concerning the similarity of NDC with NPC treated with maneb are based on a single observation, which should be independently replicated to draw a definitive conclusion. We plan to address this in future research.

In conclusion, we observed that gene expression profiles of NDC with present cultivation routine tend to alter their energetic metabolism, which reflects increased vascular and stromal processes associated with a partial loss of their neuronal identity. For now, it seems more practical to use original NS for studying ex vivo neuronal cells. Still, it is possible that by growing NDC in the presence of ROS, scavengers and/or different sources of energy cell cultures with more pronounced neuronal signatures can be obtained to render the material more useful in mass collection for psychiatric research.

Supplementary Materials: The following are available online at https:/ / www.mdpi.com/article/10 .3390 / cells10071690/s1. Figure S1. Heterogeneity of SMA in NDC; Figure S2. Matrix of Spearman's correlations between analysed expression profiles; Figure S3: Map of mutually overlapping gene sets, enriched in GSEA analysis of gene ontologies of cellular components; Figure S4: Map of mutually overlapping gene sets, enriched in GSEA analysis of gene ontologies of biological processes; Figure S5: Pathview visualisation of fold change (NDC vs. NS) of genes involved in Parkinson's disease; Table S1: List of data used on dimensionality reduction plots; Table S2: Deseq2 results of differential expression of NDC vs. NS; Table S3: GSEA results for cell component gene ontologies; Table S4: GSEA results for biological process ontologies; Table S5: GSEA results for KEGG pathways; Table S6: GSEA results for WikiPathways collection; Table S7: GSEA results for MsigDB Hallmark pathways collection.

Author Contributions: Conceptualisation and methodology-N.V.K., E.A.Z.; sample collectionT.V.L., A.E.K., A.S.T., G.Y.T., A.I.K.; cell biology-E.A.Z., E.D.M., E.B.D.; molecular biology and bioinformatics-N.V.K.; writing, original draft-N.V.K., E.A.Z.; writing, reviewing, and editingE.B.D., V.E.G.; supervision-V.E.G. All authors have read and agreed to the published version of the manuscript.

Funding: The study was supported by a grant from the Russian Science Foundation, grants no. 16-15-00056, https: / / rscf.ru/ project/16-15-00056/, accessed on 3 July 2021 (sample collection) and 2115-00124, https: / / rscf.ru/project/21-15-00124/, accessed on 3 July 2021 (RNAseq data and analysis). The part of the work that required fluorescent microscopy was supported by grant no. 075-15-20191789 from the Ministry of Science and Higher Education of the Russian Federation, allocated to the Center for Precision Genome Editing and Genetic Technologies for Biomedicine.

Institutional Review Board Statement: The study protocol and the informed consent form were approved by the Ethics Committee of the Research Institute of Mental Health (protocol No. 267 on 2016-03-04).

Informed Consent Statement: All study participants signed an informed consent form to participate in the research.

Data Availability Statement: Raw RNA-seq sequencing reads generated in this study were deposited to the SRA database, accession number PRJNA732358 (https: / / www.ncbi.nlm.nih.gov/sra/PRJNA7 32358 , accessed on 3 July 2021). 
Conflicts of Interest: The authors declare no conflict of interest. The funders had no role in the design of the study, in the collection, analysis or interpretation of data, in the writing of the manuscript or in the decision to publish the results.

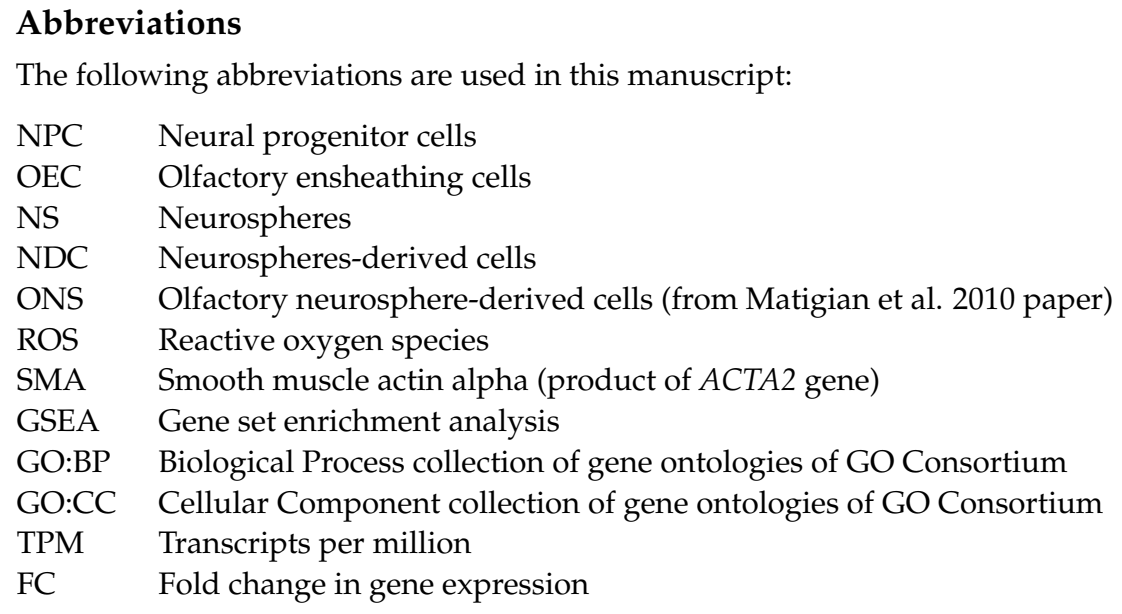

\section{References}

1. Jaffe, A.E.; Gao, Y.; Deep-Soboslay, A.; Tao, R.; Hyde, T.M.; Weinberger, D.R.; Kleinman, J.E. Mapping DNA methylation across development, genotype and schizophrenia in the human frontal cortex. Nat. Neurosci. 2016, 19, 40-47. [CrossRef] [PubMed]

2. Amiri, A.; Coppola, G.; Scuderi, S.; Wu, F.; Roychowdhury, T.; Liu, F.; Pochareddy, S.; Shin, Y.; Safi, A.; Song, L.; et al. Transcriptome and epigenome landscape of human cortical development modeled in organoids. Science 2018, 362, 6420. [CrossRef] [PubMed]

3. Schork, A.J.; Won, H.; Appadurai, V.; Nudel, R.; Gandal, M.; Delaneau, O.; Revsbech Chris-tiansen, M.; Hougaard, D.M.; Bækved-Hansen, M.; Bybjerg-Grauholm, J.; et al. A genome-wide association study of shared risk across psychiatric disorders implicates gene regulation during fetal neurodevelopment. Nat. Neurosci. 2019, 22, 353-361. [CrossRef]

4. $\quad$ Li, M.; Santpere, G.; Kawasawa, Y.I.; Evgrafov, O.V.; Gulden, F.O.; Pochareddy, S.; Sunkin, S.M.; Li, Z.; Shin, Y.; Zhu, Y.; et al. Integrative functional genomic analysis of human brain development and neuropsychiatric risks. Science 2018, 362 , eaat7615. [CrossRef] [PubMed]

5. Seshadri, M.; Banerjee, D.; Viswanath, B.; Ramakrishnan, K.; Purushottam, M.; Venkatasub-ramanian, G.; Jain, S. Cellular models to study schizophrenia: A systematic review. Asian J. Psychiatr. 2017, 25, 46-53. [CrossRef] [PubMed]

6. Das, D.; Feuer, K.; Wahbeh, M.; Avramopoulos, D. Modeling Psychiatric Disorder Biology with Stem Cells. Curr. Psychiatry Rep. 2020, 22, 24. [CrossRef] [PubMed]

7. Shao, Z.; Noh, H.; Bin Kim, W.; Ni, P.; Nguyen, C.; Cote, S.E.; Noyes, E.; Zhao, J.; Parsons, T.; Park, J.M.; et al. Dysregulated protocadherin-pathway activity as an intrinsic defect in induced pluripotent stem cell-derived cortical interneurons from subjects with schizophrenia. Nat. Neurosci. 2019, 22, 229-242. [CrossRef]

8. Marchetto, M.C.; Belinson, H.; Tian, Y.; Freitas, B.C.; Fu, C.; Vadodaria, K.; Beltrao-Braga, P.; Trujillo, C.A.; Mendes, A.P.D.; Padmanabhan, K.; et al. Altered proliferation and networks in neural cells derived from idiopathic autistic individuals. Mol. Psychiatry 2017, 22, 820-835. [CrossRef]

9. Mertens, J.; Wang, Q.W.; Kim, Y.; Yu, D.X.; Pham, S.; Yang, B.; Zheng, Y.; Diffenderfer, K.E.; Zhang, J.; Soltani, S.; et al. Differential responses to lithium in hyperexcitable neurons from patients with bipolar disorder. Nature 2015, 527, 95-99. [CrossRef]

10. Chen, H.M.; DeLong, C.J.; Bame, M.; Rajapakse, I.; Herron, T.J.; McInnis, M.G.; O'Shea, K.S. Transcripts involved in calcium signaling and telencephalic neuronal fate are altered in induced pluripotent stem cells from bipolar disorder patients. Transl. Psychiatry 2014, 4, e375. [CrossRef]

11. Sullivan, P.F.; Daly, M.J.; O'Donovan, M. Genetic architectures of psychiatric disorders: The emerging picture and its implications. Nat. Rev. Genet. 2012, 13, 537-551. [CrossRef] [PubMed]

12. Glahn, D.C.; Knowles, E.E.M.; McKay, D.R.; Sprooten, E.; Raventós, H.; Blangero, J.; Gottes-man, I.I.; Almasy, L. Arguments for the sake of endophenotypes: Examining common misconceptions about the use of endophenotypes in psychiatric genetics. Am. J. Med. Genet. B Neuropsychiatr. Genet. 2014, 165B, 122-130. [CrossRef] [PubMed]

13. Wen, Z.; Nguyen, H.N.; Guo, Z.; Lalli, M.A.; Wang, X.; Su, Y.; Kim, N.S.; Yoon, K.J.; Shin, J.; Zhang, C.; et al. Synaptic dysregulation in a human iPS cell model of mental disorders. Nature 2014, 515, 414-418. [CrossRef]

14. Pak, C.; Danko, T.; Zhang, Y.; Aoto, J.; Anderson, G.; Maxeiner, S.; Yi, F.; Wernig, M.; Südhof, T.C. Human Neuropsychiatric Disease Modeling using Conditional Deletion Reveals Synaptic Transmission Defects Caused by Heterozygous Mutations in NRXN1. Cell Stem Cell 2015, 17, 316-328. [CrossRef] [PubMed]

15. Siegert, S.; Seo, J.; Kwon, E.J.; Rudenko, A.; Cho, S.; Wang, W.; Flood, Z.; Martorell, A.J.; Ericsson, M.; Mungenast, A.E.; et al. The schizophrenia risk gene product miR-137 alters presynaptic plasticity. Nat. Neurosci. 2015, 18, 1008-1016. [CrossRef] [PubMed] 
16. Brennand, K.; Savas, J.N.; Kim, Y.; Tran, N.; Simone, A.; Hashimoto-Torii, K.; Beaumont, K.G.; Kim, H.J.; Topol, A.; Ladran, I.; et al. Phenotypic differences in hiPSC NPCs derived from patients with schizophrenia. Mol. Psychiatry 2015, 20, 361-368. [CrossRef] [PubMed]

17. Hoekstra, S.D.; Stringer, S.; Heine, V.M.; Posthuma, D. Genetically-Informed Patient Selection for iPSC Studies of Complex Diseases May Aid in Reducing Cellular Heterogeneity. Front. Cell. Neurosci. 2017, 11, 164. [CrossRef] [PubMed]

18. Volpato, V.; Smith, J.; Sandor, C.; Ried, J.S.; Baud, A.; Handel, A.; Newey, S.E.; Wessely, F.; Attar, M.; Whiteley, E.; et al. Reproducibility of Molecular Phenotypes after Long-Term Differentiation to Human iPSC-Derived Neurons: A Multi-Site Omics Study. Stem Cell Rep. 2018, 11, 897-911. [CrossRef]

19. Calof, A.L.; Mumm, J.S.; Rim, P.C.; Shou, J. The neuronal stem cell of the olfactory epithelium. J. Neurobiol. 1998, 36, 190-205. [CrossRef]

20. Féron, F.; Perry, C.; Girard, S.D.; Mackay-Sim, A. Isolation of adult stem cells from the human olfactory mucosa. Methods Mol. Biol. 2013, 1059, 107-114.

21. Evgrafov, O.V.; Wrobel, B.B.; Kang, X.; Simpson, G.; Malaspina, D.; Knowles, J.A. Olfactory neuroepithelium-derived neural progenitor cells as a model system for investigating the molecular mechanisms of neuropsychiatric disorders. Psychiatr. Genet. 2011, 21, 217-228. [CrossRef] [PubMed]

22. Borgmann-Winter, K.; Willard, S.L.; Sinclair, D.; Mirza, N.; Turetsky, B.; Berretta, S.; Hahn, C.G. Translational potential of olfactory mucosa for the study of neuropsychiatric illness. Transl. Psychiatry 2015, 5, e527. [CrossRef] [PubMed]

23. Brann, D.H.; Tsukahara, T.; Weinreb, C.; Lipovsek, M.; Van den Berge, K.; Gong, B.; Chance, R.; Macaulay, I.C.; Chou, H.J.; Fletcher, R.B.; et al. Non-neuronal expression of SARS-CoV-2 entry genes in the olfactory system suggests mechanisms underlying COVID-19-associated anosmia. Sci. Adv. 2020, 6, eabc5801. [CrossRef]

24. Gupta, K.; Mohanty, S.K.; Mittal, A.; Kalra, S.; Kumar, S.; Mishra, T.; Ahuja, J.; Sengupta, D.; Ahuja, G. The Cellular basis of the loss of smell in 2019-nCoV-infected individuals. Brief. Bioinform. 2020, 22, 873-881. [CrossRef]

25. Tabakow, P.; Raisman, G.; Fortuna, W.; Czyz, M.; Huber, J.; Li, D.; Szewczyk, P.; Okurowski, S.; Miedzybrodzki, R.; Czapiga, B.; et al. Functional Regeneration of Supraspinal Connections in a Patient with Transected Spinal Cord following Transplantation of Bulbar Olfactory Ensheathing Cells with Peripheral Nerve Bridging. Cell Transplant. 2014, 23, 1631-1655. [CrossRef]

26. Gilmour, A.D.; Reshamwala, R.; Wright, A.A.; Ekberg, J.A.K.; St John, J.A. Optimizing Olfactory Ensheathing Cell Transplantation for Spinal Cord Injury Repair. J. Neurotrauma 2020, 37, 817-829. [CrossRef]

27. Murrell, W.; Wetzig, A.; Donnellan, M.; Féron, F.; Burne, T.; Meedeniya, A.; Kesby, J.; Bianco, J.; Perry, C.; Silburn, P.; et al. Olfactory mucosa is a potential source for autologous stem cell therapy for Parkinson's disease. Stem Cells 2008, 26, $2183-2192$. [CrossRef]

28. Rhie, S.K.; Schreiner, S.; Witt, H.; Armoskus, C.; Lay, F.D.; Camarena, A.; Spitsyna, V.N.; Guo, Y.; Berman, B.P.; Evgrafov, O.V.; et al. Using 3D epigenomic maps of primary olfactory neuronal cells from living individuals to understand gene regulation. Sci. Adv. 2018, 4, eaav8550. [CrossRef]

29. Evgrafov, O.V.; Armoskus, C.; Wrobel, B.B.; Spitsyna, V.N.; Souaiaia, T.; Herstein, J.S.; Walker, C.P.; Nguyen, J.D.; Camarena, A.; Weitz, J.R.; et al. Gene Expression in Patient-Derived Neural Progenitors Implicates WNT5A Signaling in the Etiology of Schizophrenia. Biol. Psychiatry 2020, 88, 236-247. [CrossRef]

30. Matigian, N.; Abrahamsen, G.; Sutharsan, R.; Cook, A.L.; Vitale, A.M.; Nouwens, A.; Bellette, B.; An, J.; Anderson, M.; Beckhouse, A.G.; et al. Disease-specific, neurosphere-derived cells as models for brain disorders. Dis. Models Mech. 2010, 3, 785-798. [CrossRef] [PubMed]

31. Durante, M.A.; Kurtenbach, S.; Sargi, Z.B.; Harbour, J.W.; Choi, R.; Kurtenbach, S.; Goss, G.M.; Matsunami, H.; Goldstein, B.J. Single-cell analysis of olfactory neurogenesis and differentiation in adult humans. Nat. Neurosci. 2020, 23, 323-326. [CrossRef]

32. Higginson, J.R.; Barnett, S.C. The culture of olfactory ensheathing cells (OECs)-A distinct glial cell type. Exp. Neurol. 2011, 229, 2-9. [CrossRef]

33. Wrobel, B.B.; Mazza, J.M.; Evgrafov, O.V.; Knowles, J.A. Assessing the efficacy of endoscopic office olfactory biopsy sites to produce neural progenitor cell cultures for the study of neuropsychiatric disorders. Int. Forum Allergy Rhinol. 2013, 3, 133-138. [CrossRef]

34. Kryukov, A.I.; Valikhov, M.P.; Tsarapkin, G.Y.; Tovmasyan, A.S.; Arzamazov, S.G.; Kondratiev, N.V.; Kostyuk, G.P.; Golimbet, V.E. Isolation of neurospheres and neural progenitor cells from the olfactory epithelium. Vestn. Otorinolaringol. 2019, 84, 31-35. [CrossRef] [PubMed]

35. Patro, R.; Duggal, G.; Love, M.I.; Irizarry, R.A.; Kingsford, C. Salmon provides fast and bias-aware quantification of transcript expression. Nat. Methods 2017, 14, 417-419. [CrossRef] [PubMed]

36. Yu, G. Using Meshes for MeSH Term Enrichment and Semantic Analyses. Bioinformatics 2018, 34, 3766-3767. [CrossRef]

37. Luo, W.; Brouwer, C. Pathview: An R/Bioconductor package for pathway-based data integration and visualization. Bioinformatics 2013, 29, 1830-1831. [CrossRef] [PubMed]

38. Siricilla, S.; Knapp, K.M.; Rogers, J.H.; Berger, C.; Shelton, E.L.; Mi, D.; Vinson, P.; Condon, J.; Paria, B.C.; Reese, J.; et al. Comparative analysis of myometrial and vascular smooth muscle cells to determine optimal cells for use in drug discovery. Pharmacol. Res. 2019, 146, 104268. [CrossRef]

39. Kanehisa, M.; Furumichi, M.; Tanabe, M.; Sato, Y.; Morishima, K. KEGG: New perspectives on genomes, pathways, diseases and drugs. Nucleic Acids Res. 2017, 45, D353-D361. [CrossRef] [PubMed] 
40. Martens, M.; Ammar, A.; Riutta, A.; Waagmeester, A.; Slenter, D.N.; Hanspers, K.A.; Miller, R.; Digles, D.; Lopes, E.N.; Ehrhart, F.; et al. WikiPathways: Connecting communities. Nucleic Acids Res. 2021, 49, D613-D621. [CrossRef] [PubMed]

41. Liberzon, A.; Birger, C.; Thorvaldsdóttir, H.; Ghandi, M.; Mesirov, J.P.; Tamayo, P. The Molecular Signatures Database (MSigDB) hallmark gene set collection. Cell Syst. 2015, 1, 417-425. [CrossRef] [PubMed]

42. Kuusisto, F.; Costa, V.S.; Hou, Z.; Thomson, J.; Page, D.; Stewart, R. Machine learning to predict developmental neurotoxicity with high-throughput data from 2D bio-engineered tissues. Proc. Int. Conf. Mach. Learn. Appl. 2019, 2019, $293-298$.

43. Peng, C.; Lu, L.; Li, Y.; Hu, J. Neurospheres Induced from Human Adipose-Derived Stem Cells as a New Source of Neural Progenitor Cells. Cell Transplant. 2019, 28, 66S-75S. [CrossRef] [PubMed]

44. Begum, A.N.; Guoynes, C.; Cho, J.; Hao, J.; Lutfy, K.; Hong, Y. Rapid generation of sub-type, region-specific neurons and neural networks from human pluripotent stem cell-derived neurospheres. Stem Cell Res. 2015, 15, 731-741. [CrossRef]

45. Yun, J.; Rocic, P.; Pung, Y.F.; Belmadani, S.; Carrao, A.C.R.; Ohanyan, V.; Chilian, W.M. Redox- dependent mechanisms in coronary collateral growth: The "redox window" hypothesis. Antioxid. Redox Signal. 2009, 11, 1961-1974. [CrossRef] [PubMed]

46. Kim, Y.W.; Byzova, T.V. Oxidative stress in angiogenesis and vascular disease. Blood 2014, 123, 625-631. [CrossRef] [PubMed]

47. Song, S.H.; Kim, K.; Park, J.J.; Min, K.H.; Suh, W. Reactive oxygen species regulate the quiescence of CD34-positive cells derived from human embryonic stem cells. Cardiovasc. Res. 2014, 103, 147-155. [CrossRef]

48. Zhang, J.; Jiang, X.; Zhang, C.; Zhong, J.; Fang, X.; Li, H.; Xie, F.; Huang, X.; Zhang, X.; Hu, Q.; et al. Actin Alpha 2 (ACTA2) Downregulation Inhibits Neural Stem Cell Migration through Rho GTPase Activation. Stem Cells Int. 2020, 2020, 1-12. [CrossRef]

49. Jahed, A.; Rowland, J.W.; McDonald, T.; Boyd, J.G.; Doucette, R.; Kawaja, M.D. Olfactory ensheathing cells express smooth muscle alpha-actin in vitro and in vivo. J. Comp. Neurol. 2007, 503, 209-223. [CrossRef]

50. Rawji, K.S.; Zhang, S.X.; Tsai, Y.Y.; Smithson, L.J.; Kawaja, M.D. Olfactory ensheathing cells of hamsters, rabbits, monkeys, and mice express $\alpha$-smooth muscle actin. Brain Res. 2013, 1521, 31-50. [CrossRef]

51. Amoh, Y.; Li, L.; Katsuoka, K.; Penman, S.; Hoffman, R.M. Multipotent nestin-positive, keratin-negative hair-follicle bulge stem cells can form neurons. Proc. Natl. Acad. Sci. USA 2005, 102, 5530-5534. [CrossRef]

52. Srivastava, G.K.; Rodriguez-Crespo, D.; Singh, A.K.; Casado-Coterillo, C.; Fernandez-Bueno, I.; Garcia-Gutierrez, M.T.; Coronas, J.; Pastor, J.C. Chitosan feasibility to retain retinal stem cell phenotype and slow proliferation for retinal transplantation. Biomed Res. Int. 2014, 2014, 287896. [CrossRef] [PubMed]

53. Mii, S.; Amoh, Y.; Katsuoka, K.; Hoffman, R.M. Comparison of nestin-expressing multipotent stem cells in the tongue fungiform papilla and vibrissa hair follicle. J. Cell. Biochem. 2014, 115, 1070-1076. [CrossRef] [PubMed]

54. Amoh, Y.; Li, L.; Katsuoka, K.; Hoffman, R.M. Multipotent hair follicle stem cells promote repair of spinal cord injury and recovery of walking function. Cell Cycle 2008, 7, 1865-1869. [CrossRef] [PubMed]

55. Reshamwala, R.; Shah, M.; St John, J.; Ekberg, J. Survival and Integration of Transplanted Olfactory Ensheathing Cells are Crucial for Spinal Cord Injury Repair: Insights from the Last 10 Years of Animal Model Studies. Cell Transplant. 2019, 28, 132S-159S. [CrossRef]

56. Raisman, G.; Li, Y. Repair of neural pathways by olfactory ensheathing cells. Nat. Rev. Neurosci. 2007, 8, 312-319. [CrossRef]

57. Schiffer, D.; Giordana, M.T.; Mauro, A.; Migheli, A. GFAP, FVIII/RAg, Laminin, and fibronectin in gliosarcomas: An immunohistochemical study. Acta Neuropathol. 1984, 63, 108-116. [CrossRef]

58. Haddad, S.F.; Moore, S.A.; Schelper, R.L.; Goeken, J.A. Smooth muscle can comprise the sarcomatous component of gliosarcomas. J. Neuropathol. Exp. Neurol. 1992, 51, 493-498. [CrossRef] [PubMed]

59. Khanna, M.; Siraj, F.; Chopra, P.; Bhalla, S.; Roy, S. Gliosarcoma with prominent smooth muscle component (gliomyosarcoma): A report of 10 cases. Indian J. Pathol. Microbiol. 2011, 54, 51-54.

60. Biernat, W.; Aguzzi, A.; Sure, U.; Grant, J.W.; Kleihues, P.; Hegi, M.E. Identical Mutations of the p53 Tumor Suppressor Gene in the Gliomatous and the Sarcomatous Components of Gliosarcomas Suggest a Common Origin from Glial Cells. J. Neuropathol. Exp. Neurol. 1995, 54, 651-656. [CrossRef]

61. Reis, R.M.; Martins, A.; Ribeiro, S.A.; Basto, D.; Longatto-Filho, A.; Schmitt, F.C.; Lopes, J.M. Molecular characterization of PDGFR- $\alpha$ /PDGF-A and c-KIT/SCF in gliosarcomas. Anal. Cell. Pathol. 2005, 27, 319-326. [CrossRef]

62. Thiruchelvam, M.; Brockel, B.J.; Richfield, E.K.; Baggs, R.B.; Cory-Slechta, D.A. Potentiated and preferential effects of combined paraquat and maneb on nigrostriatal dopamine systems: Environmental risk factors for Parkinson's disease? Brain Res. 2000, 873, 225-234. [CrossRef]

63. Kluss, J.H.; Mamais, A.; Cookson, M.R. LRRK2 links genetic and sporadic Parkinson's disease. Biochem. Soc. Trans. 2019, 47, 651-661. [CrossRef] [PubMed]

64. Cuypers, A.; Plusquin, M.; Remans, T.; Jozefczak, M.; Keunen, E.; Gielen, H.; Opdenakker, K.; Nair, A.R.; Munters, E.; Artois, T.J.; et al. Cadmium stress: An oxidative challenge. Biometals 2010, 23, 927-940. [CrossRef] [PubMed]

65. Desplats, P.; Patel, P.; Kosberg, K.; Mante, M.; Patrick, C.; Rockenstein, E.; Fujita, M.; Hashimoto, M.; Masliah, E. Combined exposure to Maneb and Paraquat alters transcriptional regulation of neurogenesis-related genes in mice models of Parkinson's disease. Mol. Neurodegener. 2012, 7, 1-10. [CrossRef] [PubMed]

66. Colle, D.; Farina, M.; Ceccatelli, S.; Raciti, M. Paraquat and Maneb Exposure Alters Rat Neural Stem Cell Proliferation by Inducing Oxidative Stress: New Insights on Pesticide- Induced Neurodevelopmental Toxicity. Neurotox. Res. 2018, 34, 820-833. [CrossRef]

67. Zarei, M.H.; Pourahmad, J.; Aghvami, M.; Soodi, M.; Nassireslami, E. Lead acetate toxicity on human lymphocytes at noncytotoxic concentrations detected in human blood. Main Group Met. Chem. 2017, 40, 105-112. [CrossRef] 
68. Wang, X.; Martínez, M.A.; Dai, M.; Chen, D.; Ares, I.; Romero, A.; Castellano, V.; Martínez, M.; Rodríguez, J.L.; MartínezLarrañaga, M.R.; et al. Permethrin-induced oxidative stress and toxicity and metabolism. A review. Environ. Res. 2016, 149, 86-104. [CrossRef]

69. Erturan, İ.; Naziroğlu, M.; Akkaya, V.B. Isotretinoin treatment induces oxidative toxicity in blood of patients with acne vulgaris: A clinical pilot study. Cell Biochem. Funct. 2012, 30, 552-557. [CrossRef]

70. Roede, J.R.; Hansen, J.M.; Go, Y.M.; Jones, D.P. Maneb and paraquat-mediated neurotoxicity: Involvement of peroxiredoxin/thioredoxin system. Toxicol. Sci. 2011, 121, 368-375. [CrossRef]

71. Anderson, C.C.; Aivazidis, S.; Kuzyk, C.L.; Jain, A.; Roede, J.R. Acute Maneb Exposure Significantly Alters Both Glycolysis and Mitochondrial Function in Neuroblastoma Cells. Toxicol. Sci. 2018, 165, 61-73. [CrossRef] [PubMed]

72. Anderson, C.C.; Marentette, J.O.; Rauniyar, A.K.; Prutton, K.M.; Khatri, M.; Matheson, C.; Reisz, J.A.; Reigan, P.; D’Alessandro, A.; Roede, J.R. Maneb alters central carbon metabolism and thiol redox status in a toxicant model of Parkinson's disease. Free Radic. Biol. Med. 2021, 162, 65-76. [CrossRef] [PubMed] 